Invited paper

\title{
Environmental Design for Concrete Structures
}

\author{
Koji Sakai $^{1}$
}

Received 5 October 2004, revised 16 November 2004

\begin{abstract}
Concrete is the most important material employed in public works and building construction projects. The large amount of concrete production causes large energy consumption, resources depletion, $\mathrm{CO}_{2}$ emissions, and other environmental impacts. This paper describes the environmental aspects of concrete and proposes environmental design as a new design paradigm for concrete structures. It also describes design examples to illustrate the rationality of environmental design.
\end{abstract}

\section{Introduction}

According to the Gaia hypothesis (Joseph 1993) by meteorologist James E. Lovelock and microbiologist Lynn Margulis, "the earth's climate and atmospheric environment are controlled by animals, plants and microorganisms living on the earth." There is no doubt that the earth has an extremely rare environment in the overwhelmingly vast universe. Its entire equilibrium is thought to be maintained by direct and indirect mutual dependence of various creatures from bacteria to humans. While the atmosphere of the earth in its early days was almost entirely composed of carbon dioxide like that of Venus and Mars, it currently consists of $78 \%$ nitrogen, $21 \%$ oxygen and $0.03 \%$ carbon dioxide. The earth has maintained a finely balanced environment that supports the survival of life for a long time. Human activities, however, are beginning to seriously affect this environment. It is said that the ancestors of mankind emerged some 5 million years ago, and now more than 6 billion people live on the earth. Such a large number of people consume enormous amounts of resources and energy to secure their living environment, and these amounts are rising with increasing speed. This situation poses a threat to the "Gaia control" of the global environment. Disruption of the regulating function of the global environment directly and indirectly affects human health, primary production, biodiversity and social assets.

The first warning on the finitude of resources was expressed in a report to the Club of Rome, entitled "The Limits to Growth" (Meadows et al. 1972). This was in 1971. In the following year, 1972, the United Nations Conference on the Human Environment was held in Stockholm, where global-scale environmental issues were discussed, the Statement on Human Environmental Quality expressing the duty of humans to protect the environment was released, and the United Nations Environment Program (UNEP) was established as an or-

\footnotetext{
${ }^{1}$ Professor, Safety Systems Construction Engineering, Kagawa University, Takamatsu, Japan. E-mail: sakai@eng.kagawa-u.ac.jp
}

ganization for its implementation. In 1987, the United Nations World Commission on Environment and Development published the Brundtland Report (WECD 1987) and presented the following concept of sustainable development:

"Development that meets the needs of the present generations without compromising the ability of future generations to meet their own needs"

In 1992, 20 years after the Stockholm Conference, the United Nations Conference on Environment and Development (Earth Summit) was held in Rio de Janeiro, where the Rio Declaration concerning the environment and development as well as the Agenda 21 action plan to implement it, were adopted. At the Earth Summit, the importance of "sustainable development" to maintain the balance between environmental conservation and economic growth was clarified, and this concept is now recognized as a guiding principle for various activities.

In 1997, the Third Conference of the Parties to the United Nations Framework Convention on Climate Change (COP3) was held in Kyoto, where the Kyoto Protocol for the reduction of greenhouse gases was adopted. According to this protocol, it was decided to reduce the emission of greenhouse gases in all advanced nations by 5.2\% from 1990 to between 2008 and 2012 . The reduction target for Japan is $6 \%$. The Kyoto Protocol introduced the "emission trading" system, which enables international trading of greenhouse gas emission limits, and the "clean development mechanism," which is a project-based flexible mechanism under which advanced countries can claim credits for reductions in greenhouse gas emission through projects that they implement in developing countries without a greenhouse gas reduction target, and use these credits to meet their own target. However, the effect of the Kyoto Protocol following the start of its implementation in the near future remains unclear due to the opposition of the United States, which is responsible for approximately one-fourth of the world's total carbon dioxide emissions.

Carbon taxes, which are imposed on fossil fuels for the purpose of controlling carbon dioxide emissions, has already been introduced in Northern Europe, Denmark, Germany and other countries, and the Japanese Ministry 
of the Environment is considering the introduction of such a tax by 2005. Emission trading of greenhouse gases has also begun, mainly in Europe. In Japan, the Ministry of the Environment has presented the "Guidelines for calculation of greenhouse gas emissions from businesses," and the Ministry of the Economy, Trade and Industry as well as the Ministry of the Environment are conducting trial emission trading.

Although the range of environmental issues, which are considered to be the greatest challenge of the $21 \mathrm{st}$ century, is wide, measures and actions based on advanced ideas must be taken steadily and responsibly to solve those problems. The field of construction is no exception. This paper describes the environmental aspects of concrete in particular, and proposes environmental design as a new design paradigm for concrete structures. It also includes design examples to illustrate the rationality of environmental design.

\section{Environmental aspects of concrete}

Environmental issues can generally be divided into global-scale environmental aspects such as greenhouse gases, regional environmental aspects such as noise and resource extraction, and living environmental aspects related to houses and other limited spaces. While environmental aspects related to concrete may include those related to cement, aggregates, admixtures and other materials, transport, repair and strengthening, demolition and recycling, as well as elution from concrete, this paper describes aspects related to materials, demolition/recycling, and elution.

\subsection{Cement}

Figure 1 shows changes in cement production in Japan (Japan Cement Association 2003). Cement production was $19,462,000$ tons in 1960 , peaked at $99,267,000$ tons in 1996, and decreased to 73,803,000 tons in 2003. Figure 2 shows the estimated cement production of the world in 2002 and 2020 (Jahren 2003). According to this estimate, the increase in production will be significant in Asia and Russia, with rates of increase of approximately $24 \%$ and $137 \%$, respectively. The estimated total production in 2020 will be as much as 2,132 million tons. On the simple assumption that an average of 0.87 tons of $\mathrm{CO}_{2}$ is generated when 1 ton of cement is produced (Humphreys et al. 2002), total $\mathrm{CO}_{2}$ emissions will be approximately 1.4 times the amount currently emitted in Japan, or 1.33 billion tons. Figures 3 and $\mathbf{4}$ show the amount of $\mathrm{CO}_{2}$ emitted by cement production in the world in 2000 and unit-based emissions (Humphreys et al. 2002). It can be seen that the amount of $\mathrm{CO}_{2}$ emitted in China is incomparably large, and that unit-based $\mathrm{CO}_{2}$ emissions were the smallest in Japan and the largest in the United States.

Humphreys et al. demonstrated that cement consumption is proportional to GDP in low-income areas and proportional to population in high-income areas, and made medium- and long-term estimations of cement consumption based on the four scenarios shown in Fig. 5 (Humphreys et al. 2002). Scenario A1 is the case where income gaps between developing and advanced nations will decrease dramatically and population growth will be low. In this scenario, cement consumption will peak half way through this century and gradually decrease after that. Scenario B1 is basically the same as A1, but there is a shift from a material to a service/information-oriented society. In this case, while the cement consumption trend is the same as in Scenario A1, the absolute quantity will be smaller. Scenario A2 shows the case when income gaps between developing and advanced nations do not decrease and high population growth is expected. In this scenario, cement consumption will increase dramatically. Scenario B2 is basically the same as A2, but with slow population growth. In any case, cement consumption is expected to increase almost uniformly until the middle of this century, to reach 4 to 6 billion tons, or approximately 2.3 to 3.5 times the current production, by 2050 .

Various types of waste and byproducts are currently used for cement production. Figures 6, 7, and $\mathbf{8}$ show the conditions of use of blast-furnace slag, fly ash and waste tires in Japan (Japan Cement Association 2003). A variety of other types of waste are also used for ce-

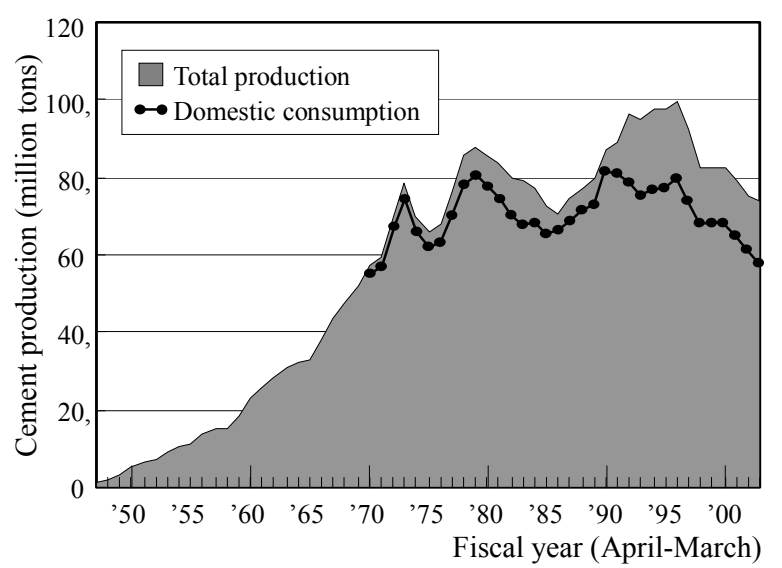

Fig. 1 Cement production in Japan (Japan Cement Association 2003).

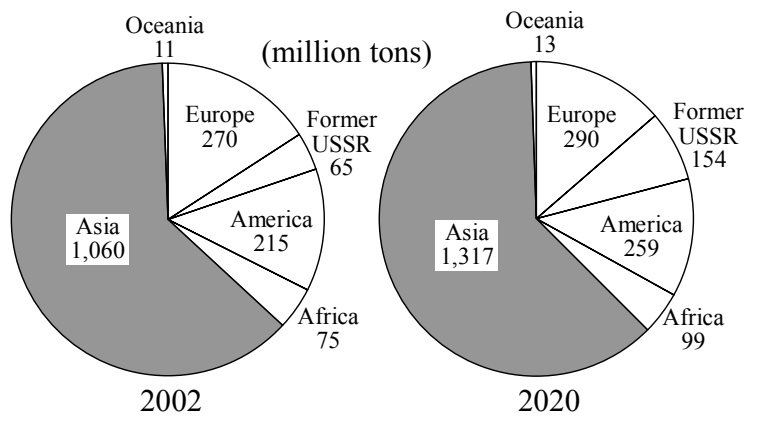

Fig. 2 Estimated world cement consumption in 2002 and 2020 (Jahren 2003). 
ment production. In other words, a life-extending effect on resources and reduction in the environmental impact of waste treatment can be promoted through effective use of waste.

\subsection{Aggregates}

Aggregates make up approximately $70 \%$ of the volume of concrete, and the shape and particle size of aggregate greatly affect the quality of concrete. Figures $\mathbf{9}$ and $\mathbf{1 0}$ show changes in the production of coarse and fine aggregates, respectively, for ready-mixed concrete by supply source (Ministry of Economy, Trade and Industry 2003). Regarding coarse aggregates, supply from rivers has decreased dramatically, and crushed stone now makes up approximately $70 \%$ of the total. The use of river sand as fine aggregate has also decreased dramatically. While sea sand and mountain/land sand currently make up $20 \%$ and $40 \%$, respectively, of the total, use of crushed sand is expected to increase in the future because the extraction of sea sand will be banned almost throughout the entire Seto Inland Sea area by 2006. Due to environmental problems, however, development of new quarries is restricted and problems are expected in the future.

While conversion from a social system of mass production, consumption and disposal to a recycling-oriented one is required, and many measures, including legal ones, have been taken in recent years, a large amount of waste is still discharged. From the viewpoint of pressure on landfill and safety, urban and industrial waste is disposed of through high-temperature melting. Slag is produced as a residue of such melting, and its use as an aggregate for concrete is being considered (Nishigori et al. 2004 and Matsuka et al. 2004). Although it is ideal to recycle waste completely, disposal by melting is an inevitable option under the present circumstances.

\subsection{Admixture minerals}

Admixture minerals such as blast-furnace slag, fly ash and silica fume have been used for effective use of industrial byproducts and improvement in quality of concrete. These admixture minerals are known to make the microstructure of concrete denser through chemical reactions and their filling effect. As mentioned above, cement has a great effect on the environmental impact of concrete structures due to large $\mathrm{CO}_{2}$ emissions during cement production. Although reinforcing steel bar production also generate a large amount of $\mathrm{CO}_{2}$, it is considered difficult to find a material that replaces reinforcing steel bars. Active use of these admixture minerals instead of cement is therefore considered to be a way of reducing environmental impact in the construction of reinforced concrete structures.

Figure 11 shows changes in blast-furnace slag production in Japan (Nippon Slag Association 2004). Blast-furnace slag is frequently used as an ingredient of blast-furnace cement. The rate of blast-furnace cement

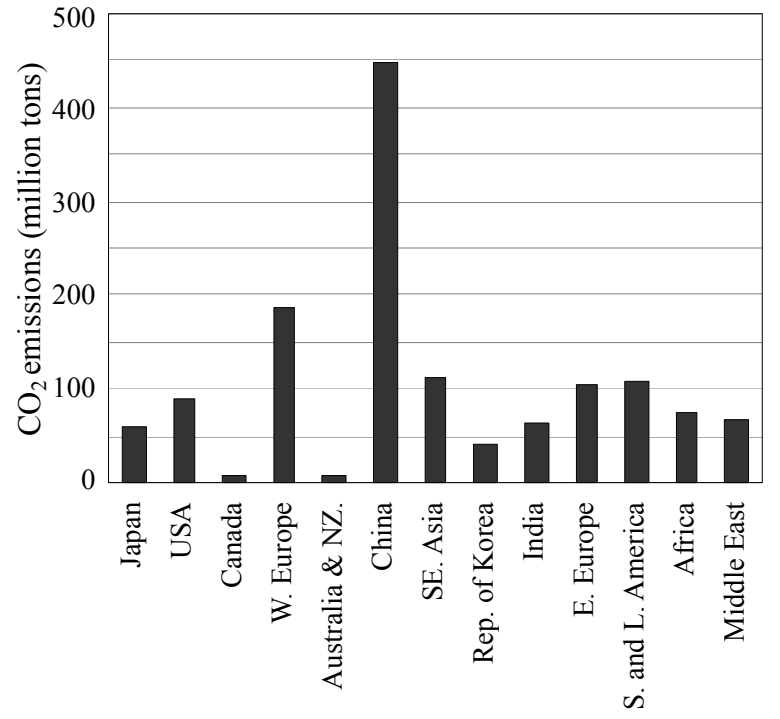

Fig. $3 \mathrm{CO}_{2}$ emission from cement industry in 2000 (Humphreys et al. 2002).

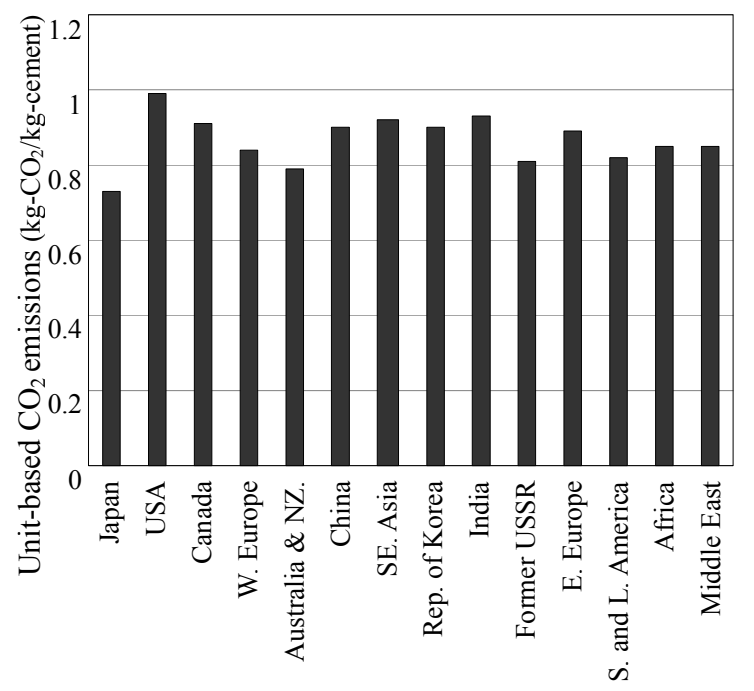

Fig. 4 Unit-based $\mathrm{CO}_{2}$ emission in cement manufactures (Humphreys et al. 2002).

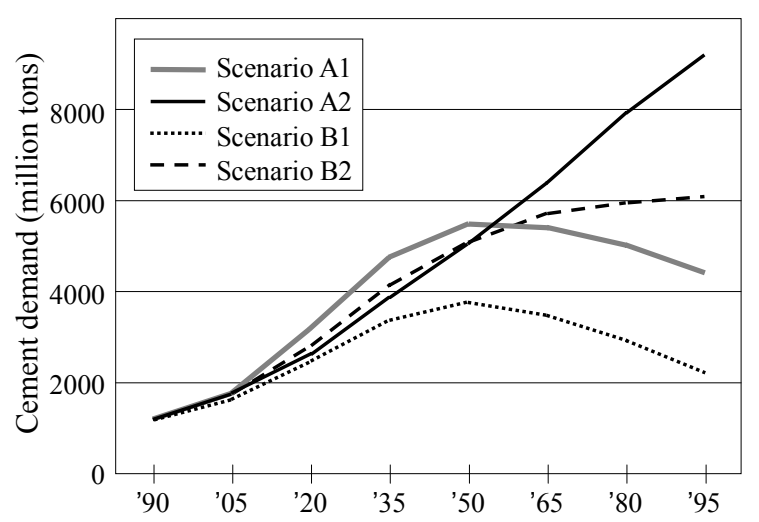

Fig. 5 Estimated cement demand (Humphreys et al. 2002). 


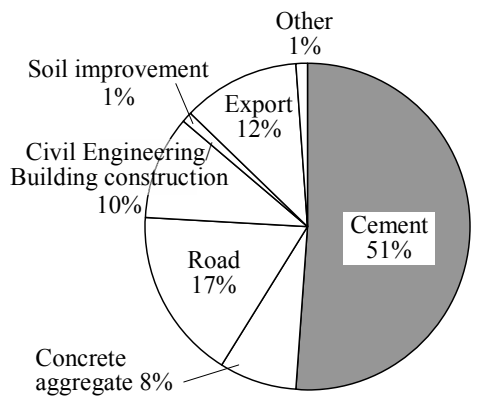

Fig. 6 Utilization of blast furnace slag in 2001 (total amount $\fallingdotseq 23$ million tons) (Japan Cement Association 2003).

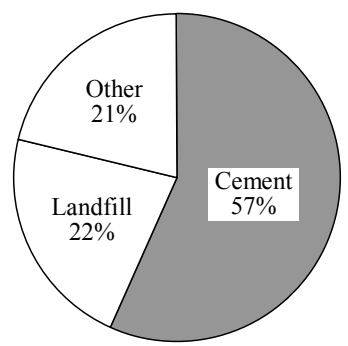

Fig. 7 Utilization of fly ash in 2001 (total amount $\fallingdotseq 6.8$ million tons) (Japan Cement Association 2003).

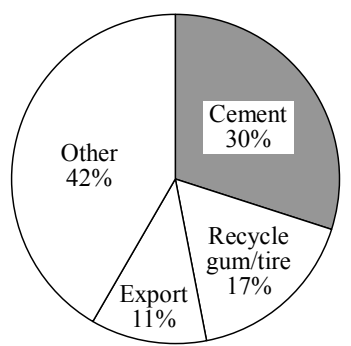

Fig. 8 Utilization of waste tires in 2001 (total amount $\fallingdotseq 1.06$ million tons) (Japan Cement Association 2003).

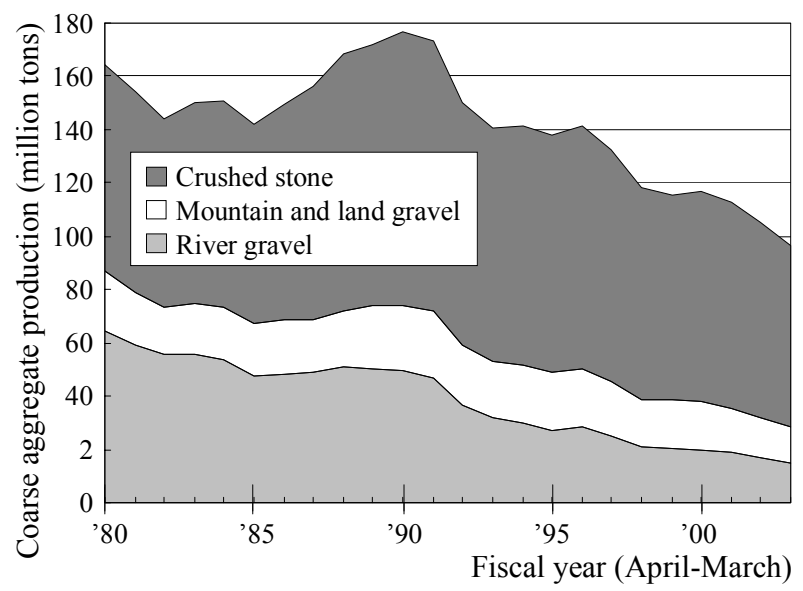

Fig. 9 Coarse aggregate production for concrete in Japan (Ministry of Economy, Trade and Industry 2003).

in current cement production in Japan is approximately $23 \%$, indicating that effective use of blast-furnace slag is progressing. Figure 12 shows changes in the generation of coal ash in Japan (Center for Coal Utilization, Japan 2004). Coal ash is mostly used as an ingredient for cement production, and fly ash cement production represents only $0.1 \%$ of total cement production.

Figure 13 shows the estimated global production of admixture minerals in 2002 and 2020 (Humphreys et al. 2002) that may be used as a means to reduce $\mathrm{CO}_{2}$ emissions resulting from the production of concrete. The estimated admixture minerals production is approximately $60 \%$ of the estimated cement production in 2020 , and it will be possible to dramatically reduce $\mathrm{CO}_{2}$ through the effective use of such admixture minerals.

\subsection{Demolition and recycling}

Advanced nations have constructed an enormous number of concrete structures for more than half a century. Although concrete structures were thought to maintain their durability for a long period of time, deterioration phenomena have actually occurred in many structures at relatively early stages, showing that rational durability

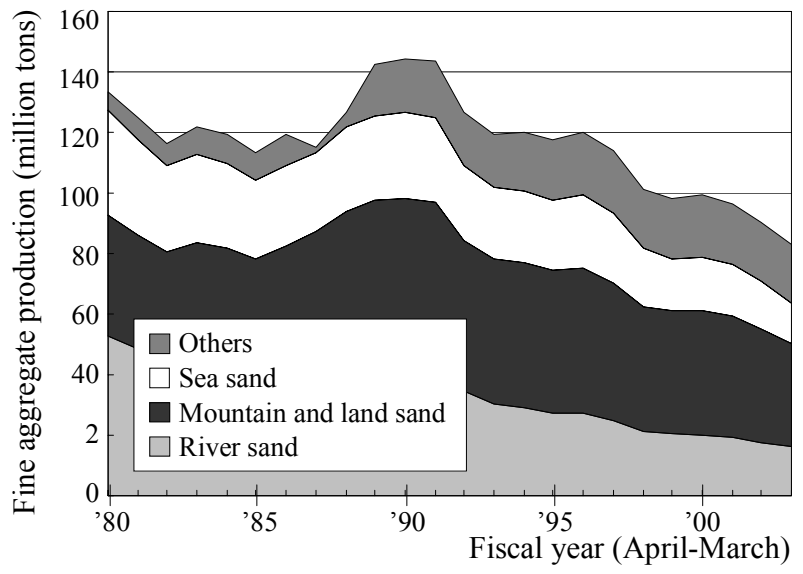

Fig. 10 Fine aggregate production for concrete in Japan (Ministry of Economy, Trade and Industry 2003).

design and appropriate construction are extremely important. There are two options for the large stock of concrete structures that currently exist - to extend their lives by repair and strengthening, or to renew them. Renewal involves the demolition of concrete structures.

Figure 14 shows a trial calculation of the discharge of construction byproducts in Japan (Development Bank of Japan 2002). According to this calculation, the discharge of construction byproducts in Japan will exceed 300 million tons in 2010 and 400 million tons in 2030, which is double and almost triple, respectively, 2000 levels. More than half of that is concrete, followed by asphalt concrete that makes up approximately $25 \%$ of the total. Concrete has mainly been recycled as a sub-base, and recycled aggregates are extremely rare. Since demand for concrete as a sub-base is expected to decrease, it is necessary to realize the recycling of aggregate resources by improving the technology for recycling aggregates from demolished concrete. Although efforts are currently made to practically apply concrete incorporating aggregates recycled by advanced treatment (Kuroda et al. 2004 and Yonezawa et al. 2001), there are still technical problems with general use. 


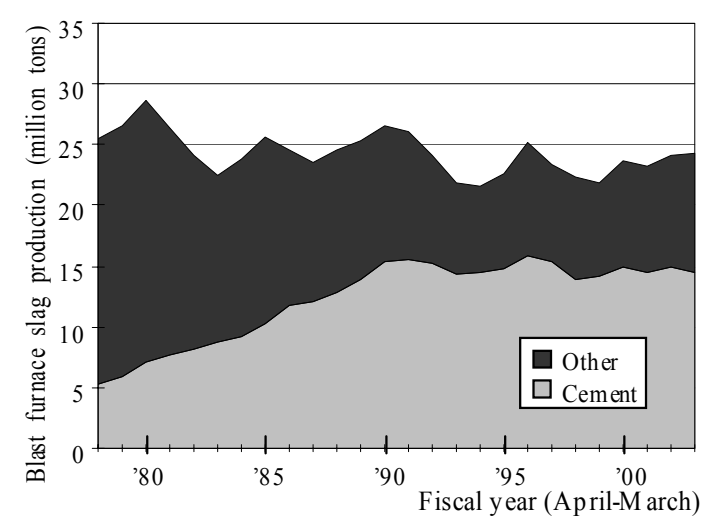

Fig. 11 Blast furnace slag production in Japan (Nippon Slag Association 2004).

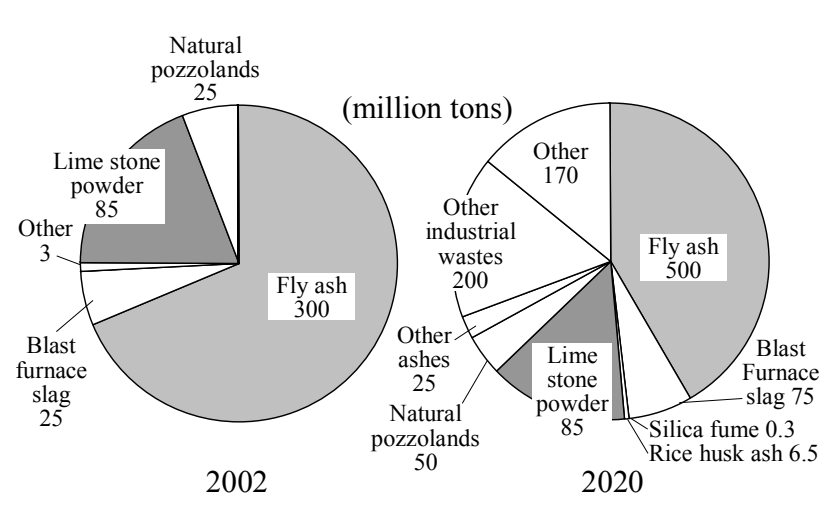

Fig. 13 Estimated world admixture minerals production in 2002 and 2020 (Jahren 2003).

At present, 26 billion tons of material is used annually in the world, including approximately 20 billion tons of aggregates for construction, 1 billion tons for steel production, 3 billion tons from forests, and 700 million tons for the production of gold (Brown 2002). In Japan, the amount of resources used for the construction industry is approximately 1.1 billion tons, which represents almost half of the total amount for all industries, 2.4 billion tons. Considering this situation, recycling of demolished concrete as an aggregate resource is extremely significant from the viewpoint of environmental conservation.

\subsection{Eluting}

Concrete is generated by a chemical reaction between cement and water. While the main ingredients of cement are limestone and clay and various byproducts or waste are also used for production, these minor sub-materials are contained in cement. It is therefore possible that these minor sub-materials will elute from concrete under certain conditions. There is also the phenomenon of hydrates dissolving in water. Although these factors will

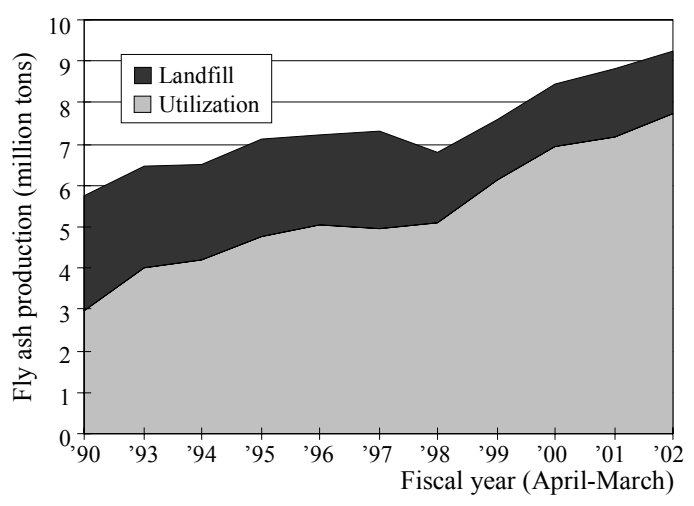

Fig. 12 Fly ash production in Japan (Center for Coal Utilization, Japan 2004).

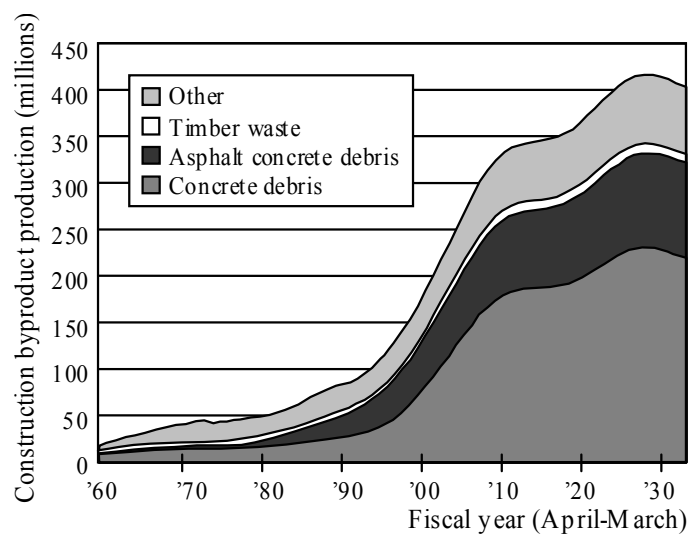

Fig. 14 Estimated construction byproduct production (Development Bank of Japan 2002).

rarely cause problems under normal conditions, not enough information has been obtained. The effects of substances related to endocrine disrupting chemicals (environmental hormones), which are used in chemical admixtures, have not been clarified either.

\section{Environmental design}

The Ministry of Land, Infrastructure and Transport drafted the Ministry of Land, Infrastructure and Transport Environmental Action Plan in June 2004 for the purpose of achieving environmentally friendly land, infrastructure and transport administration. The main purpose of this action plan is to consolidate measures for the reduction of environmental impact throughout the entire lifecycle of a project from the conception and planning stage to implementation, maintenance/management and abolishment. It promotes the inclusion of environmental aspects (conservation, restoration and creation) in a planning stage, life-extension of public facilities by introducing asset management (comprehensive asset management method) and lifecy- 
cle management of infrastructure development, including zero-emission of construction works and green purchase. It also promotes environmentally friendly means of transportation and housing/buildings to cope with global warming, development of evaluation methods and countermeasure technologies to boost the environmental performance of structures involving $\mathrm{CO}_{2}$ emission and waste discharge throughout their lifecycles, as well as dissemination and promotion of energy-saving operation systems and low-fuel-type construction machinery for the reduction of carbon dioxide emissions from construction machinery. This action plan, however, does not mention environmental aspects of structural types, materials and construction methods in the field of civil engineering. It is obvious that reduction of environmental impact must be taken into consideration in the design and construction of civil engineering structures.

Current design methods concerning concrete structures have been organized with a focus on "safety." Although "durability" has recently been incorporated in design as a function of time (JSCE 2002), it must be said that the environmental viewpoint, which is an essential element of the life-extension of structure and resource efficiency, was extremely weak (Sakai 2002).

Life-extension of a structure can have two meanings - setting a long life at the time of new design and setting a new life through repair after the structure is put into service. In either case, the life of the structure is set on a certain basis. From an environmental viewpoint, it can generally be thought that life-extension is directly related to reduction of the environmental impact.

"Design" of structures can be considered in a narrow or a broad sense. The former encompasses creative acts that decide the shape and size of structures. The latter also includes the acts of "verifying" safety and durability of structures, and can also be rephrased as "performance design," which includes the setting of performance requirements and their verification.

In safety design, the safety of a structure is verified from the relationship between the cross-sectional force determined by the load and structural type, and the design sectional bearing force of an actual member section. In durability design, the durability is verified from the relationship between the performance evaluation index calculated based on a prescribed life cycle and the limit value. The design service life of a structure is determined by considering the service life required of the structure, the maintenance/management method, environmental conditions and the durability and economic efficiency required of the structure (JSCE 2002).

Promoting reduction in the environmental impact in the design of a concrete structure, taking global warming and resource efficiency into account, can be considered basically the same as safety and durability design. Although indexes for safety and durability verification express completely different qualities, the possibility of setting physical or chemical limits is common to both of them. Needless to say, destruction is the limit situation of safety. Regarding durability, for example, the limit of chloride ion concentration is determined based on the condition that corrosion does not occur on reinforcing bars. Also, if the carbonation of concrete progresses to the position of reinforcement, this will create a corrosion environment for reinforcing bars. In this case, concrete cover is set as a limit value in design.

When considering the global environment, resource efficiency and other environmental aspects in the design of a concrete structure, selecting indexes and setting their limit values can become major problems. Although setting of physically and chemically significant limit values, as with safety and durability, is difficult in this case, a similar scenario can be developed. For example, global warming due to greenhouse gases progresses, abnormal weather and a rise in sea levels may occur on a global scale. These would cause disasters and changes in the biological environment, and would eventually threaten the survival of mankind. Under the present circumstances, however, it must be said that scientific prediction of these conditions is extremely difficult. We suspect that something is happening, based on scientific signs of the global warming phenomenon and fragmentary changes in the environment. As a result, nations dedicate enormous energy to hammer out agreements for the reduction of greenhouse gases and promote improvement in the environment through legislation and other measures. Legal controls on a broad framework are not necessarily effective. For example, total emissions of greenhouse gases in Japan in 2002 were 1,331 million tons, exceeding total emissions in 1990, the reference year set by the Kyoto Protocol, by 7.6\% (Ministry of the Environment 2004). It will therefore be extremely difficult to achieve the goal of the protocol. This is due to the inability to incorporate mechanisms that enforce reduction of greenhouse gases into economic activities because of conflicts of interests.

On the other hand, limit values concerning noise and toxic substances are set by law. Although their bases are also obscure to a large extent, they are functioning for the time being. It can actually be felt that these measures directly affect human health. In the old days, exhaust gases from automobiles caused serious air pollution and strict regulations against such pollution helped improve the lives of residents of urban areas. Today, automobiles that use liquid hydrogen as fuel and discharge only water are in the process of becoming a reality.

We have two options. One is not to regulate greenhouse gases until a serious situation occurs. The other is to introduce a social and economic system including a mechanism for reducing greenhouse gases.

In the design of concrete structures, the mechanism for reducing greenhouse gases, for example, can be divided into the following four cases, depending on the party that sets limits:

1. Setting limits by law 
2. Setting limits by the owner

3. Setting limits by the designer

4. Setting limits by a third party

Although it is difficult to implement such approaches immediately under the current circumstances, it is important to construct a design system that takes such future directions into account. In other words, no matter what the main factor is, to set the limit value, a system that enforces consideration of greenhouse gas emission reduction in design should be introduced. The same can be said of other environmental aspects. If regulation values exist, they can be used as limit values.

The design of concrete structures means comprehensive implementation of safety, serviceability, durability and environmental design. Environmental design also includes construction and recycling. Extreme cases were assumed from the environmental aspect. For example, by using high-performance materials instead of conventional materials, durability can be improved dramatically and a structural type that can significantly decrease the amount of material can be achieved. There is no particular problem concerning serviceability, and environmentally required performance can also be satisfied. There may also be a case where requirements concerning safety, serviceability, durability and environmental performance can be satisfied by a combination of conventional materials and industrial byproducts. Although these design methods satisfy all three required performances - structural (safety, serviceability), durability, and environmental performance, they completely differ from conventional design systems in that the environment is incorporated into design. Thus, "environmental design" will be used here as a term to express a new design concept that even includes design that satisfies required environmental performances. It can simply be called "design," when consideration to the environment in design becomes common in the future.

The entire flow of environmental design taking the above into account can be as follows:

1. Client briefing

2. Conceptual design

- Selection of performance requirements based on the law and clients' briefing:

Structure, service life and environment

- Matters to be considered in the environment: Materials, energy, water and discharge of substances, land use, biodiversity

3. Setting of performance requirements

- Structural performance

- Durability performance

- Environmental performance

(1) Setting of legal regulations and their limits or conditions (It is possible to set limit values or conditions that are stricter than legal regulations.)

(2) Setting of requirements other than legal regulations and their limits or conditions(Reduction of $\mathrm{CO}_{2}$ by $5 \%$ from the standard, presentation of comparative design cases, requirements of consideration to the environment, etc.)

4. Selection of materials, shape and size, and construction/maintenance/recycling methods

5. Evaluation and verification of structural performance

6. Evaluation and verification of durability performance

7. Evaluation and verification of environmental performance

Once environmental design is completed, the next step is actual "construction," followed by "inspection" and "service." "Record" can serve as extremely important information for understanding the entire project and implementing subsequent maintenance management.

The term "environmental performance" will be discussed next. For example, if a car has the ability to run $20 \mathrm{~km}$ per liter it is said that "the car has excellent environmental performance," which means that this car has an environmentally friendly performance in that it is capable of running as far as $20 \mathrm{~km}$ per liter of gasoline. In the same way, if $\mathrm{CO}_{2}$ emission from production of a certain material is low, that material can be described as having "high environmental performance." Concerning materials that contain toxic substances, those with low toxic contents can be considered to have "high environmental performance." It can also be said that there is no particular problem with expressing a construction machine with low noise or a land use plan with high land use efficiency or low impact on biodiversity as ones with excellent "environmental performance." We can set "performance" ourselves according to a reasonable standard, and the "environment" can also be handled in the same way. Although the term "structural performance" is used, it does not mean that a structure itself has the ability to do something. What we provide or give to it is simply considered as "performance."

If $\mathrm{CO}_{2}$ is considered a requirement besides legal regulations for setting the environmental performance, its reduction limit can be set at $5 \%$ based on the Kyoto Protocol. This is based on the agreement to reduce greenhouse gas emissions by $5.2 \%$ from 1990 to between 2008 and 2012 in all advanced nations. Because it is difficult to set an absolute standard of $\mathrm{CO}_{2}$ emission, it is considered realistic to prepare documents that explain how 5\% reduction is achieved individually and to verify their validity. It is also possible to simply require design options regarding $\mathrm{CO}_{2}$ reduction without setting a concrete reduction requirement, and choose one of them, taking other performances into consideration. This series of actions is regarded as verification. It is important to clarify actual consideration to the environment by a certain system. ISO/DIS 15686 (Buildings and constructed assets-Service life planning- Part 6: Guideline for considering environmental impacts) (ISO/DIS 15686 2002) provides a framework to evaluate safety and other technical points and economic and environmental considerations by setting the required 
performance based on briefings, project goals and the law, and a verification system for each requirement. In this standard, setting requirements consist of building performance, service life, environmental impact, and whole life cost.

\section{Examples of environmental design}

\section{1 $\mathrm{RC}$ rigid frame viaduct}

Railway crossings cause traffic congestion and have large impacts on the regional environment and traffic safety problems. To solve these problems, it is necessary to introduce overhead crossings at railway facilities. Construction of railway overpasses in urban environments where crossings are used may involve a variety of restrictions in many cases. The subject of this case study is the construction of a $\mathrm{RC}$ rigid frame viaduct for a railway line adjacent to an urban residential area. Figure 15(a) shows a general view of the viaduct. This viaduct is a four-span $\mathrm{RC}$ rigid frame bridge that is $60.00 \mathrm{~m}$ in total length. A rigid frame bridge usually has footing beams at the joints between piles and columns as shown in Fig. 15(b), to absorb unevenness in the bearing capacity of piles and ensure seismic performance. Passages and sufficient space for construction are necessary for the installation of footing beams. Installation of footing beams is therefore physically difficult if there is a nearby residential area and railway lines for temporary operation must be secured. In such a case, it is possible to consider a structural type that ensures the required seismic performance by increasing the bearing capacity of piles and reinforcing the joints between piles and columns with steel tubes as shown in Fig. 15(c). The $\mathrm{CO}_{2}$ emission from materials, transport and construction was calculated for structural types with or without footing beams. Figure 16 shows the results. $\mathrm{CO}_{2}$ emissions related to footing beams account for approximately $30 \%$ of the total. $\mathrm{CO}_{2}$ emissions related to beams, scaffolds and falseworks were larger in the presence of footing beams. On the other hand, $\mathrm{CO}_{2}$ emissions related to slabs, columns and piles were larger in the absence of footing beams. $\mathrm{CO}_{2}$ emissions related to slabs were larger in the absence of footing beams than in their presence, because PC plates were used as buried forms in the former. By adopting a structure without footing beams, $\mathrm{CO}_{2}$ emissions could be reduced by approximately $28 \%$ in all. Figure 16 also illustrates the ratios of $\mathrm{CO}_{2}$ emissions from materials, transport and construction. Emissions due to construction were almost halved by eliminating footing beams.

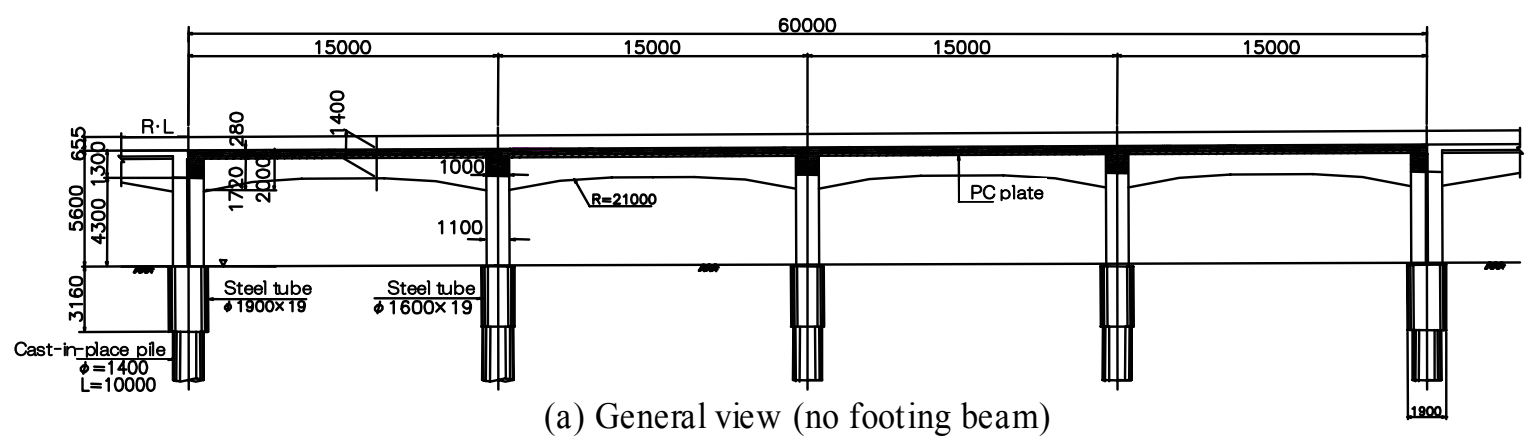

(a) General view (no footing beam)

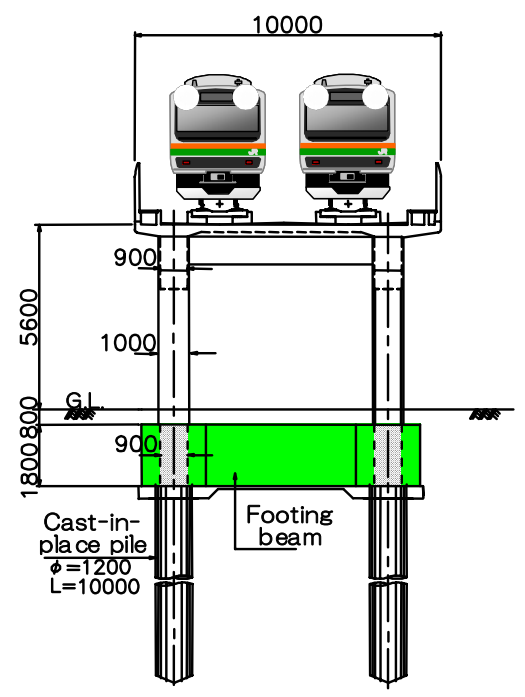

(b) Sectional view (with footing beam)

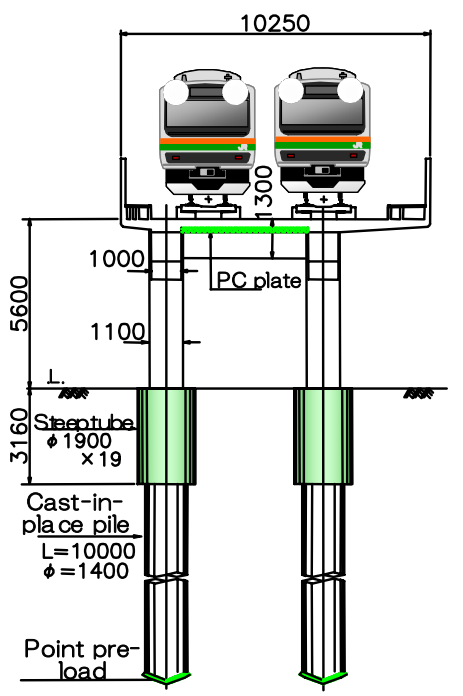

(c) Sectional view (without footing beam)

Fig. $15 \mathrm{RC}$ rigid frame viaduct. 
$\mathrm{CO}_{2}$ emissions from materials accounted for approximately $90 \%$ of the total.

While it was decided to construct an $\mathrm{RC}$ rigid frame viaduct without footing beams in this case due to the problems of construction work and period, $\mathrm{CO}_{2}$ emission could be reduced as a result. Selection of this structural type reduces surrounding environmental influences such as traffic congestion, noise, vibration and air pollution that accompany construction work. In other words, it can be said that this structural type and construction method was chosen for reduction of environmental impact. This case thus indicates the possibility of "design" in which the required structural performance can be ensured and environmental impact can be reduced at the same time.

\subsection{Super high-strength steel fiber-reinforced concrete pedestrian bridge}

Super high-strength steel fiber-reinforced concrete (RPC) can dramatically reduce the dead weight of a structure because of its excellent strength characteristics. The foundation can be thinner as a result and may also lead to the reduction of construction costs. The maintenance cost can also be reduced because of the excellent durability of RPC. Table 1 and Fig. 17 show the mix proportions and the bending behavior of RPC (Tanaka 2003). Steel fiber of $0.2 \mathrm{~mm}$ in diameter, $15 \mathrm{~mm}$ in length and $2800 \mathrm{~N} / \mathrm{mm}^{2}$ in tensile strength was mixed. RPC was used to construct a 50.2-meter-long 2.4-meter-wide outer-cable prestressed bridge with an unreinforced box-type closed section with variable web height (upper slab thickness $=5 \mathrm{~cm}$, web thickness $=8$ $\mathrm{cm}$ ). Figures 18 and 19 show the general view and cross section of this bridge, respectively. The dead weight of the bridge was $560 \mathrm{kN}$. Precast blocks consisting of three types of segment blocks were manufactured at a precast concrete product plant. They were cured twice. Sheet curing was first conducted in an open-air environment, followed by 48 -hour steam curing at $90^{\circ} \mathrm{C}$. If this bridge was to be designed as a three-span, $\mathrm{PC}$ simple slab bridge (hereinafter referred to simply as "PC bridge"), which is thought to be the most rational for its conditions, its dead weight would be $2,780 \mathrm{kN}$, approximately 5 times that of the RPC bridge. Figure 20 shows a general view of the hypothetical PC bridge.

In this case, the $\mathrm{CO}_{2}$ emissions from the production of the materials, steel forms, and RPC beams or pre-tension hollow beams, the transport and the construction were calculated for RPC and PC bridges. Figure 21 shows the results. Although the volume of concrete could be reduced by approximately $40 \%$ by changing from a PC bridge to an RPC bridge, the $\mathrm{CO}_{2}$ emitted by the superstructure of the RPC bridge was considerably higher than that of the PC bridge, because the unit cement volume was much larger than that of PC concrete, in which cement of $400 \mathrm{~kg} / \mathrm{m}^{3}$ and of 300 $\mathrm{kg} / \mathrm{m}^{3}$ was assumed in a superstructure and substructure, steam curing was conducted for the production of RPC

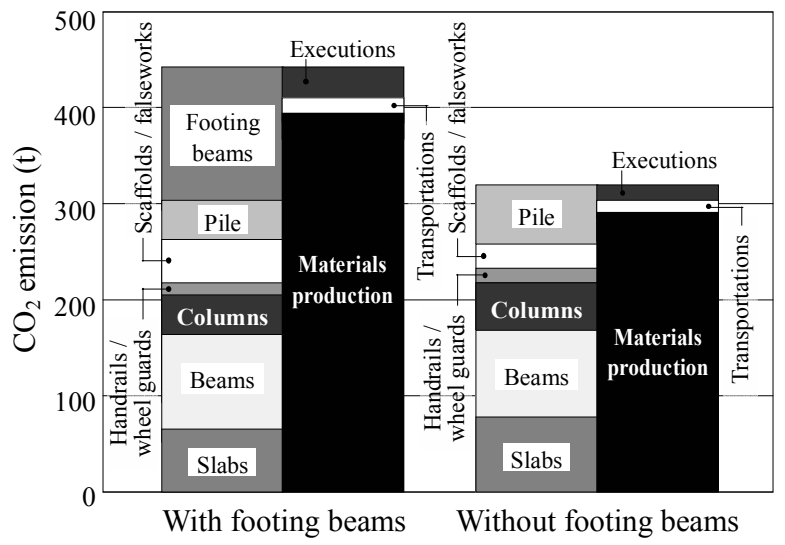

Fig. $16 \mathrm{CO}_{2}$ emissions of $\mathrm{RC}$ rigid frame viaduct.

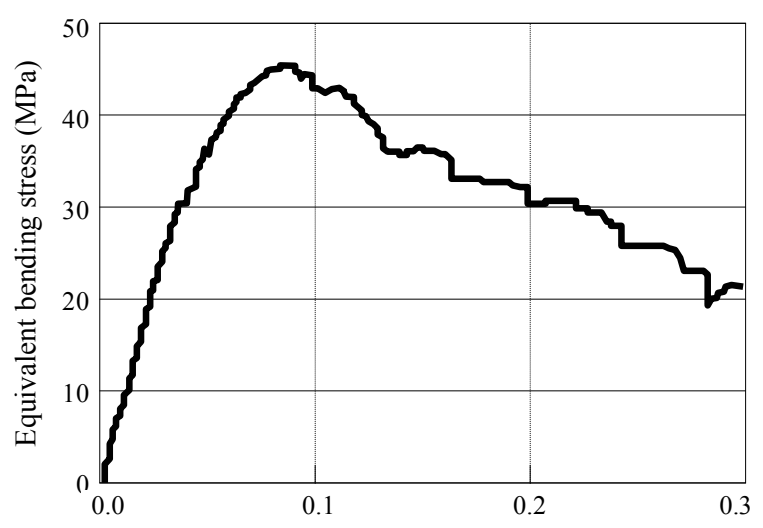

Fig. 17 Flexural behavior of super-high strength steel-fiber reinforced concrete (Tanaka et al. 2004).

Table 1 Mix proportions of RPC ${ }^{21)}$.

\begin{tabular}{|c|c|c|c|c|}
\hline Water & Cement & $\begin{array}{c}\text { Grain } \\
\text { (quartz, sand, } \\
\text { etc.) }\end{array}$ & $\begin{array}{c}\text { Steel } \\
\text { fibers }\end{array}$ & $\begin{array}{c}\text { Super- } \\
\text { plasticizer }\end{array}$ \\
\hline 180 & 818 & 1479 & 157 & 24 \\
\hline
\end{tabular}

Unit: $\mathrm{kg} / \mathrm{m}^{3}$, the water includes water content in superplasticizer, $19 \mathrm{~kg} / \mathrm{m}^{3}$

beams and unconvertible steel forms were used for beam production. In the case of the $\mathrm{PC}$ bridge, however, the $\mathrm{CO}_{2}$ emitted by production of materials related to the construction of steel piles and piers was high, and the final results indicated that the $\mathrm{CO}_{2}$ emitted from the RPC bridge was approximately $25 \%$ lower than that from the PC bridge.

This case thus indicates the possibility of "design" by which required structural performance can be ensured and total environmental load can be reduced at the same time by a new structural type through the use of a super high-performance material.

\subsection{Future of environmental design}

Neither of the cases of environmental design shown here were intended to reduce the environmental impact 


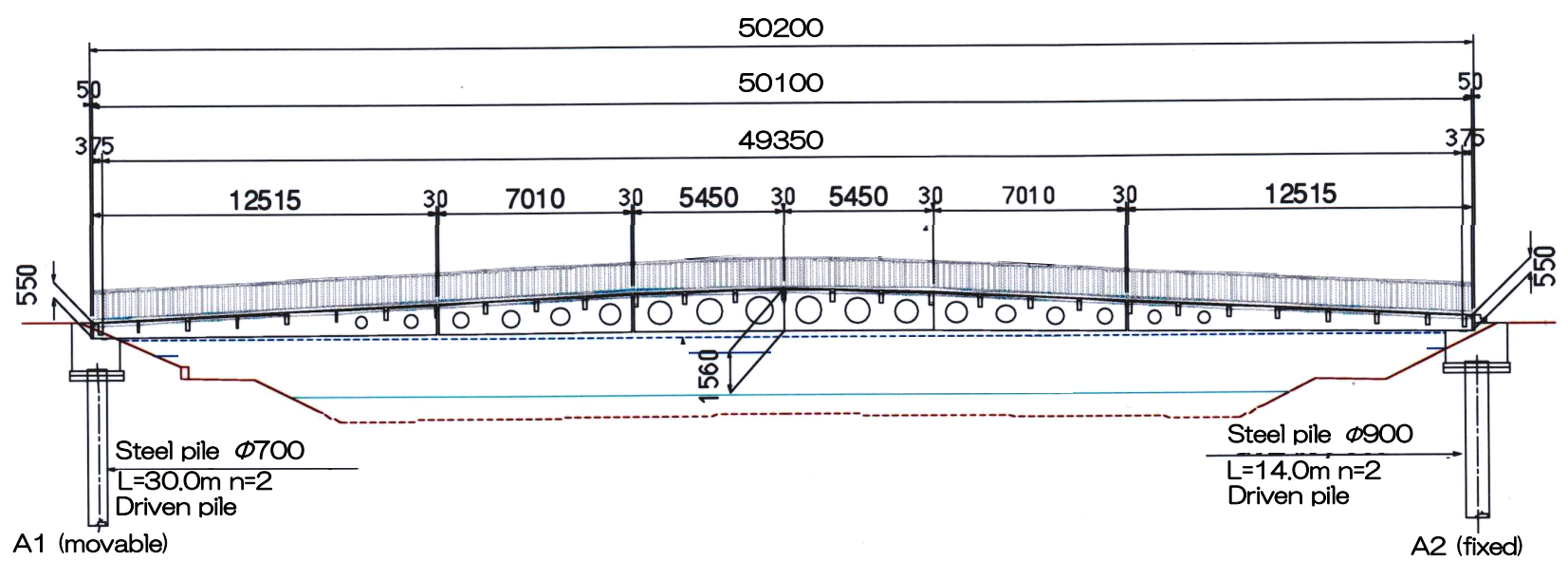

Fig. 18 General view of RPC bridge.

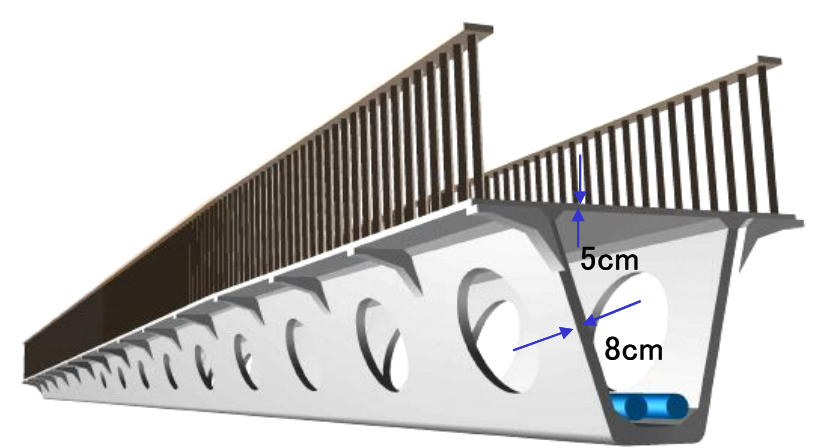

Fig. 19 Sectional view of RPC bridge.

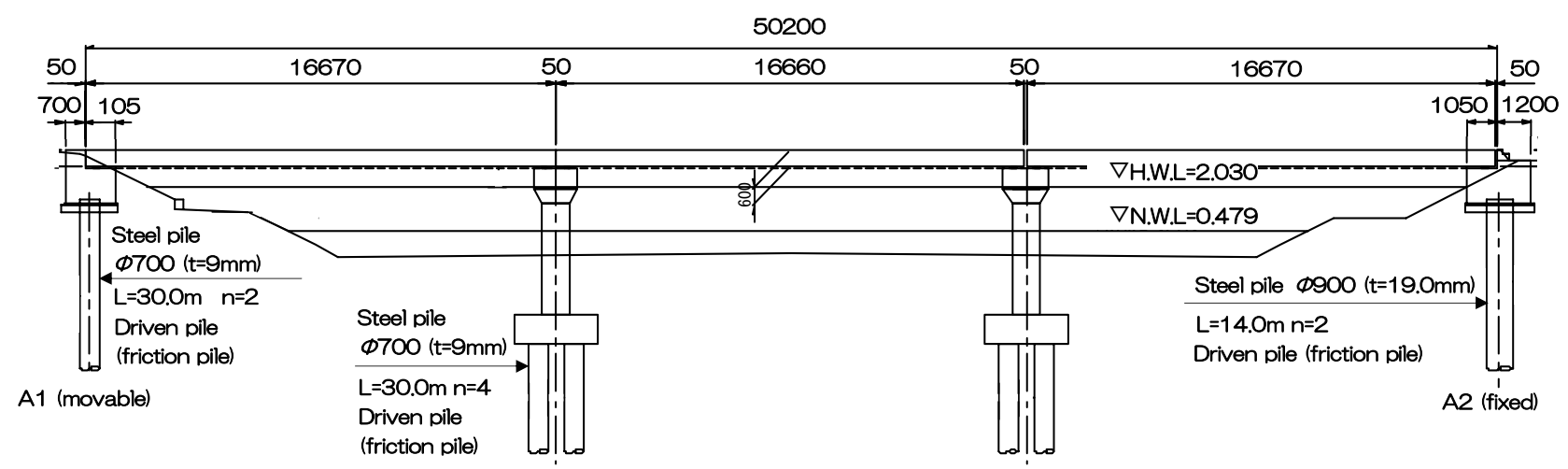

Fig. 20 General view of hypothetical PC bridge.

at the time of construction. The $\mathrm{RC}$ rigid frame viaduct was a result of restrictions in construction and the pedestrian bridge the result of the application of a new material. Both of these approaches, however, realized a dramatic reduction in environmental impact. This indicates the rationality of adding environmental performance to structural and durability performances required in conventional design systems.

Introduction of environmental performance in "environmental design" may lead to innovative materials and structures. In other words, the "environment" is a treasure house of technical development.

\section{Concluding remarks}

It can be emphasized that the "environment" is the essence of various problems we have. We will eventually have to face the issue of how long mankind can survive on this precious planet. Even though we are aware of the urgent nature of this matter, it will be difficult to 


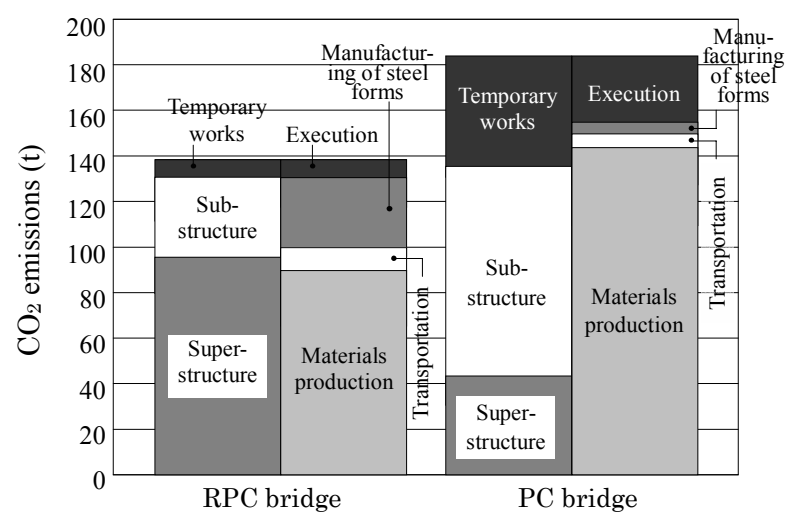

Fig. $21 \mathrm{CO}_{2}$ emissions of RPC and PC bridges.

give up old ways and the perceived advantages they afford. It is obvious that there will be much resistance to changing the values and systems involved in conventional social and economic activities, because any system involves conflicts of interests.

A different view, however, can be based on the hypothesis that consideration to the "environment" in our social and economic activities can be the "essence of work" by itself. In other words, there is no work that does not involve the environment, because everything has environmental aspects that will eventually affect the survival of mankind. It is important to incorporate such an "environmental mechanism" into social and economic activities. In the household electrical and automobile industries, environmental aspects such as energy saving and elimination of fossil fuels are becoming the focus of business. While the fundamental problem in these fields is the short service life of products, this can be solved by product development that takes recycling into consideration.

On the other hand, while civil engineering and building structures have long lives, their number is overwhelmingly large as they form the base for human social and economic activities. This means that they consume enormous resources and are responsible for emissions of huge amounts of greenhouse gases. Although there is no question about the extreme importance of introducing effective systems to reduce environmental impacts in the field of construction, the present circumstances do not necessarily foster such a trend. This is because the advantages of reducing environmental impacts have not been clarified in the field of construction, unlike the household electrical and automobile industries. Thus, only the minimum obligations concerning the environment are fulfilled within the scope of legal regulations.

Considering such circumstances, we first have to understand the status of the environmental impact in the field of construction as broadly and correctly as possible. Next, possibilities should be sought by conducting environmental design as indicated in this paper. The ideal scenario is to reduce construction and maintenance costs by promoting reduction of environmental impacts. Thus, technical development for environmental impact reduction can be facilitated. The author believes that such a paradigm shift in the design of concrete structures will create the new frontier in the field of concrete technology.

At the fib Commission 3, where the author serves as chairman, basic examination of environmental design has been conducted (fib 2004). The development of "Guidelines for environmental design" is currently under way. The Task Group on Environmental Aspects under the Specification Subcommittee of the Concrete Committee of the Japan Society of Civil Engineers, where the author serves as convener, is also collecting and sorting information on environmental aspects and is planning to eventually produce "Recommendations for environmental design of concrete structures (tentative)". The Subcommittee on the evaluation of the environmental impact of concrete, the Concrete Committee of the Japan Society of Civil Engineers has also presented useful information (JSCE 2004). The author believes that we can achieve global-scale accountability for environmental problems in the field of concrete if we can disseminate environmental design in the near future through these activities, establish an "integrated design" system to cover structure, durability and environment comprehensively and set them as ISO standards common to the entire world.

\section{Acknowledgments}

I would like to express my deepest gratitude to $\mathrm{Mr}$. Tomoaki Moriyama of the Research and Development Center, East Japan Railway Company, and Mr. Eiji Owaki, Ms. Asuko Ishihara and Hiroyuki Musha of Taisei Technology Center, Taisei Corporation, for providing their full support for the case studies on the RC rigid frame viaduct and super high-strength steel fiber-reinforced concrete pedestrian bridge, respectively.

\section{References}

Brown, L. R. (2002). "Eco-Economy, Building an Economy for the Earth ( Translated to Japanese by Katsuya Fukuoka).” Ienohikari Kyokai.

Center for Coal Utilization, Japan. (2004). "Survey Report on Utilization of Fly Ash in Japan." (in Japanese)

Development Bank of Japan. (2002). "Urban Renewal and Resource Recycling: For the Creation of a Resource Recycling Society." Research Report/No. 33. (in Japanese)

Draft International Standard ISO/DIS 15686-6. (2002). "Building and Constructed Assets - Service Life Planning - Part 6: Guideline for Considering Environmental Impacts."

fib. (2004). "Environmental Design." Bulletin 28.

Humphreys, K. and Mahasenan, M. (2002). "Toward a Sustainable Cement Industry, Climate Change Sub-Study 8", World Business Council for 
Sustainable Development.

Jahren, P. (2003). "Greener Concrete-What are the options? The $\mathrm{CO}_{2}$ case." STF22A03610 Report, SINTEF.

Japan Cement Association (2003). "Cement Handbook."(in Japanese)

Japan Society of Civil Engineers. (2002). "Standard Specifications for Concrete Structures-2002, Materials and Construction." (in Japanese)

Japan Society of Civil Engineers. (2004). "Environmental Impact Evaluation of Concrete (II) ." Concrete engineering series 62. (in Japanese)

Joseph, L. E. (1993). "GAIA : The Growth of an Idea (Translated to Japanese by Y. Takahashi)." TBS Britannica.

Kuroda, Y., Hashida, H. and Miyaji, Y. (2004). "Application of recycled aggregate concrete to building structure." Cement \& Concrete, Japan Cement Association, No. 685, 8-18. (in Japanese)

Matsuka, T., Sakai, K., Yamaji, N. and Watanabe, K. (2004). "Flexural crack of reinforced concrete members using molten slag from municipal waste." Proceedings of the JCI Annual Convention, 26 (2), 907-912. (in Japanese)

Meadows, D. H., Meadows, D. L., Randers, J. and Behrens III W.W. (1972). "The Limits of Growth, A Report to the Club of Rome (Translated to Japanese by S. Okita).", Diamond. Inc.

Ministry of Economy, Trade and Industry (2003). "Yearbook of Ready-Mixed Concrete Statistics."(in Japanese)
Ministry of the Environment (2004). (in Japanese) "http://www.env.go.jp/earth/ondanka/ghg/gaiyo.html." Nishigori, W., Sakai, K., Matsuka, T. and Fujimori, T. (2004). "Effect of the mutual-rubbing reformation of molten slag as fine aggregate for concrete." Proceedings of the JCI Annual Convention, 26 (1), 69 -74. (in Japanese)

Nippon Slag Association. (2004). "Yearbook of Iron and Steel Slag Statistics.” (in Japanese)

Sakai, K. (2002). "A new design framework of concrete structures - environmental design." Special issue: Prolonging life for concrete structures, Concrete Journal, Japan Concrete Institute, 40 (5), 53-58. (in Japanese)

Tanaka, Y., Musha, H., Shimoyama, Y. and Kobayashi, T. (2003). "Application development of ultra high strength fiber reinforced concrete for pre-stressed concrete bridge." Concrete Journal, Japan Concrete Institute, 41 (3), 26-32. (in Japanese)

The World Commission on Environment and Development (WECD)(1987). “Our Common Future." Oxford U.P.

Yonezawa, T., Kamiyama, Y., Yanagibashi, K., Kojima, M., Arakawa, K. and Yamada, M. (2001). "A study on a technology for producing high quality recycled coarse aggregate." Journal of the Society of Materials Science, 50 (8), 835-842. (in Japanese) 